\title{
4
}

\section{GLOBAL PERSPECTIVES OF IMMERSIVE JOURNALISM}

\author{
Sarah Jones
}

$\mathrm{VR}$ is such a fascinating medium for journalism because two huge factors of VR are the feeling of transporting you to some place, and secondarily, but just as importantly, connecting you to the people inside of that place.

Chris Milk 2015

Technology companies like Oculus and Samsung have been instrumental in driving immersive journalism forward. With support in the form of development funding, news organizations have been encouraged to look at how immersive journalism can develop in the virtual reality space. This has been evident in the form of initiatives like Oculus'VR for Good and HTC Vive's VR for Impact. Technology companies have seen journalism and factual storytelling as a way to reach a new audience, away from the gaming and computer science industries where it has previously dominated. There has been indicative support for this. With The New York Times sending 1.2 million headsets to subscribers in November 2016 and virtual reality (VR) units or studios developing in companies like Al Jazeera, BBC and The Guardian, new ways of using the technology to drive journalism have been identified.

At the heart of this is the widespread belief that VR has the potential to change perspectives in understanding stories. It is the idea that stories told through VR can "transport viewers to places and events - to understand the world in new ways" (Watson 2017, 7). In the seminal paper on immersive journalism, Nonny de la Peña defined it as the production of news where "people can gain first-person experiences of the events or situation described in news stories" $(2010,291)$. The ability and impact that transporting an audience to a different place to engage in a news story in a direct way is contextualized in conversations around empathy and ethics, as discussed in Chapter 5 and 8 respectively in this book. What needs to be understood here is the positioning of immersive journalism in a global context. 
With this in mind, this chapter analyzes the importance of immersive journalism to understand global issues and perspectives and the challenges that this raises when faced with a global digital divide. Through a series of case studies, immersive journalism practices from across the world will be identified and the impact that this has on the journalist, the journalism, and the experience.

\section{The global context for immersive journalism}

Journalism is about stories. It is about taking people to different places, providing information, and allowing for an objective account of a story to be told. The first wave of VR in the 1960s focused on the possibilities with the advancement of the technology. It was in the second wave, when the technology was more advanced and organizations like NASA could start to utilize it for education and training, that we saw the first ideas emerge around how VR could be applied to media practices. The early work on the ideas ofVR (Hamit 1993; Rheingold 1991) began introducing VR as the next logical step for communications, with Biocca and Levy (1995) theorizing that VR would enable journalists to "conquer time and space" by creating "a sense on the part of audiences of being present at distant, newsworthy locations and events". When narratives are developed to transport an audience to different places and cultures, the necessity to understand the global context of immersive journalism is clear.

What is evident, though, is the digital divide: the idea that there is an inequality in access and information to communication technologies. In 2019, there are still groups in America with limited access to the internet, with 30\% of rural America still lacking what the Federal Communications Commission consider as adequate broadband (Politico 2018). This includes communities within certain income brackets, ethnicities, and geographical locations, which then has implications for employment, education, and the economy. It is even more prevalent when we look at the digital divide globally, where the "Internet has developed unevenly throughout the world” (Guilen \& Suárez 2005, 681).

The 2018 Digital Use Suite (We Are Global and Hoot Suite, Kemp 2018) showed slight improvements in the distribution of internet access across the world. Internet penetration rates are found to be still low across Central Africa (12\%) and Southern Asia (36\%), but they are also the fastest-growing regions for adoptions. The number of users in Africa has increased by more than $20 \%$ year on year. Users in Benin, Sierra Leone, Niger, and Mozambique have also more than doubled in one year.

When considering the global digital usage in the context of journalism, the number of mobile phones is also important to consider, a valuable addition to the journalist's toolbox and something that will be discussed later in this chapter. The same report found more than two-thirds of the global population has a mobile phone, but still below $50 \%$ in Central Africa. The connection speeds vary considerably, which is important to note when this is looked on as a tool for digital storytelling and connectivity. Norway, Singapore, and the United Arab Emirates all boast speeds in excess of $50 \mathrm{Mbps}$, compared with Bangladesh at 5.2 Mbps andVenezuela at $7.9 \mathrm{Mbps}$. 
The rise of digital journalism, responding to changes in platforms and technologies, has been as a direct result of the use of mobiles, as well as by innovations in digital narratives (Vázquez-Herrero \& López-García 2017), so the existence of a digital divide raises concerns around representation of voices when considering the global context of immersive journalism. There is an increase in the adoption of digital journalism, but the divide will continue to exist when countries cannot freely access the technology.

The 2018 ICFJ report, The State of Technology in Global Newsrooms, addressed some of these challenges, providing a clear indication of the ways in which the digital divide is impacting news production and consumption. The findings of the report detail the digital media skills used regularly in the newsroom. What is classed as first-tier skills are those used by at least half of the newsrooms across the world and include stories and comments on social media (72\%) and using digital photography (61\%). Video production skills and audio production skills are classed as second-tier skills, used by at least one-third of newsrooms. Video skills are used in $49 \%$ and audio $42 \%$. Mobile reporting is used in 34\% newsrooms. The third-tier skills are where we find journalists working with VR and 360-degree video, however it is represented in only 21\% newsrooms.

New revenue models for news businesses have adapted and changed over the past decade (REF) and this is especially difficult for newsrooms in developing countries. More than $70 \%$ of organizations in sub-Saharan Africa and Latin America/ Caribbean found this to be a major challenge in adapting to new revenue models (ICFJ 2018). The rise of immersive journalism and virtual reality platforms was found to be particularly problematic and the biggest challenge for newsrooms in South Asia (53\%), East/Southeast Asia (47\%) and sub-Saharan Africa (46\%). It was the least of a challenge for newsrooms in Europe, with only 15\% finding it problematic.

With $21 \%$ of global newsrooms reporting to be using VR, this may be more down to teams experimenting with 360-degree filming or still photography on a tilt-and-rotate platform on social media. Certainly previous studies (Jones 2017) demonstrate the number of newsrooms producing VR regularly is significantly lower. The concern is around representation, with the question needing to be asked as to how do we ensure stories are being represented by journalists on the ground? The majority of stories produced within an immersive journalism format are usually around issues in the developing world (Jones 2017) to allow the idea of working in someone else's shoes, or essentially meeting the purpose of journalism "to provide people with information they need to understand the world" (Kovach \& Rosenstiel 2014). It is essential to show that work is being done on the ground by journalists to establish immersive journalism practices in a global context.

\section{Immersive journalism for a global perspective}

With support from organizations like Journalism 360, Oculus andVive, organizations have been able to develop immersive journalism practices. Through analysis of 
these organizations the potentiality of immersive journalism to offer authenticity of the story is understood. The organizations that have been developing since 2015 onwards are all committed to storytelling from a diverse range of voices to prevent the portrayal of communities and cultures through a foreign lens, something that will now be discussed.

Electric South was developed to build an ecosystem of immersive journalists in Africa. Based in Cape Town, South Africa, the organization operates under the belief that "new technologies must open up spaces for original voices and underrepresented narratives" (Electric South). The argument for this came out of a need for diversity and inclusivity within emerging media. As Kopp argued in 2017, "the problem is there is no balance in the African narrative being told - the pieces were all made by people from North America and Europe and they were not telling the whole story" (Kopp 2017).

The challenges facing the developing world in diversifying storytelling through new technologies is clear. As Kopp argues, it is harder and more expensive to buy equipment, it is harder to get the equipment in and out of countries, visas are expensive and difficult to get, the community is small so it is harder to share resources, there are barriers and complications for distribution, and phones have limited data or WiFi connectivity.

Despite the challenges, the global need for creating networks of diverse immersive journalists is evident as a way to avoid blind spots that emerge if only one group of society dominates a particular field, and it is through an ecosystem of inclusion that avoids this (Sinclair 2017). Through a residency approach, immersive storytellers in Africa have come together annually since 2015 with Electric South to collaborate, develop skills and look at emerging media forms to tell stories. The programs have been supported by the Ford Foundation. As one participant said following the 2018 camp, "they plant the seed for the new generation to come" (Afande 2018).

Although not specific to immersive forms, the workshops cover augmented reality, virtual reality, machine learning, and depth kit perceptions. It means that the participants are contributing to the development of immersive media, how it is used, produced, and consumed, before the rules have been set. As mainstream journalism has developed, it has relied on learning from previous traditions of narrative, imagery and style, whether online formats (Steensen 2010), radio and podcasting (Berry 2016; Cwynar 2015) or television (Wood 1986; Tuchman 1978). The rules in immersive media still have not been set and as RYOT co-founder Bryan Mooser (in Hernandez 2017) argues "journalism is changing". Due to the complexities of the combination of technical, artistry, and journalistic understandings, there is a collaborative approach with no one skillset dominating. This is allowing for inclusivity and levelling the playing field for diversity. As Kombo Chapfika, an Electric South 2018 participant, said, "there are no rules, the hierarchies haven't been fully set yet".

Similarly, it echoes the driving force behind Contrast VR, perhaps one of the most established immersive studios, with the explicit mandate to promote diversity and inclusivity in immersive journalism. 
ContrastVR was founded in 2017 as the immersive studio of Al Jazeera. It originally began as the testing lab within Al Jazeera Digital with the aim to explore emerging technology and how that could be used for more immersive storytelling and, specifically, for journalism. Zahara Rasoul is the Editorial Lead, noting in 2018 that the main challenge is an understanding of what can be done; we have the tech but you don't have the storytelling that is actually going to have the impact that we think the technology combined with the storytelling can have" (Rasoul 2018).

The aim for Contrast is authenticity and to use immersive journalism as a way to break down the view of stories being told through the lens of a foreign reporter. Through a project where cameras and training were provided, they sought to enable journalists who did not have access to the kit to take charge of their own narratives.

One of the goals of Contrast is to be able to enable local journalists and storytellers to take charge of their own narratives and to tell their own stories rather than only foreign journalists going into a place and telling those stories.

Rasoul 2018

The initiative, My People, Our Stories, has trained filmmakers across the Za'atari refugee camp, South Sudan, and Rio de Janeiro, Brazil. It is seeking to add authentic voices to the concerns around representation in the media, something that has been the subject of a large body of academic research in recent years (Krimsky 2002; Heinrich 2012; Joye 2009), where there has been a disparity in the voices and tone of stories when presented through a foreign reporter's lens. This was clearly reflected in the comments from one of the ContrastVR workshops,

When residents of the favela see a local journalist that is covering a story, they trust that the narrative won't be stereotyped or told in a distorted way. But when there is a journalist from outside there is a relationship of fear and even revolt, as favelas and their residents are almost always depicted as marginalized by the corporate media.

Thamyra Thâmara, in Contrast, Medium 2018

More than 100 journalists and filmmakers have been trained by Contrast in two years (Contrast 2018) using the technology to give agency to different communities. Joi Lee, a Contrast producer, argues, "when those impacted by the issue are at the forefront of shaping the narrative, the stories become more informed and nuanced to reflect the realities on the ground" (Lee, Contrast 2018).

The above two case studies demonstrate the interest and desire to develop skills and expertise in immersive media to promote diversity and inclusivity. This is applicable in terms of content but also within the development of an emerging field. However, despite a range of workshops and interest in showing work, without securing funding for developing immersive content, the market becomes fragmented. There is a need for creators to continually develop and build on work, testing new methods and technologies as they develop, otherwise there are no resources for people to get better (Kopp, in conversation 2019). The impact 
that this is having in the Global South is clear. There is government resource in countries including Canada (CMF), France (CNC), and the UK (Creative $\mathrm{XR}$ ), so the industry is developing. With funding limited in the Global South for development and production, "people aren't building a body of work" (Kopp in conversation 2019).

Distribution is also a key concern with finding and engaging audiences to show and make immersive media more accessible. Electric South has taken this with a top-down and bottom-up approach by targeting museums and art galleries at the top end and libraries and community spaces at the bottom. The driver has been to take it out of "self-selecting" spaces (Kopp, in conversation 2019) and to ensure that access to technology finds a wide group of people. It is a similar approach to that of NowHere Media in India and the VR experience, Love Matters India (www. lovematters.in). With technological challenges in the infrastructure, the experience needed to have an offline distribution channel for maximum impact. The experience was launched in restaurants in Delhi and Mumbai. In a partnership with the Delhi Metro, viewing booths were set up with mobile-based headsets, but there were challenges with electricity and limitations to streaming experiences.

Research in the case studies has shown the challenge for immersive journalism across the world is aligned to technological capabilities and the digital divide. With a significant need to promote diversity and inclusivity within the news medium, it can be argued that lessons from the rise of mobile journalism can help embed the industry to offer diverse voices and native narratives.

\section{The influence of mobile journalism}

There is tradition in using emerging technology to diversify journalistic practices. Since 2008, the rise of mobile journalism has empowered journalists across the world to tell stories. Early research (Bivens 2008) examined how traditional journalistic practices were beginning to be influenced by mobile technologies and, through an ethnographic study of 40 newsrooms, found the role that the citizen journalist played through documenting events on mobile devices to aid "reporting of contested topics or regions fraught with accessibility issues" (113). Studies on early adopters (Koponen \& Väätäjä 2009) found the benefits for journalists, particularly for efficiency. Mobile allowed great access to documentary stories, particularly in places where traditional media crews were banned (Quinn 2013), so this has proved valuable in countries with poor media freedom and also by allowing reporters to get closer to the story (Karhunen 2017). The same study described mobile-led stories as being "more genuine", "authentic" "more intimate", "faster", and "more informal" (Karhunen 2017, 118).

There has been an increase in the number of media organizations wanting to recruit journalists with mobile-making skills (Wenger et al. 2014), though concerns around the professionalization has been questioned with particular reference to expert knowledge, professional autonomy, routines, and the influence of external organizations (Blakenship 2016). 
It is necessary to put to one side the questions concerning quality, workflows, and techniques as this is not the focus of this chapter. However, it is important to consider how the rise of mobile journalism has enabled diverse voices to reach new audiences and capture a new form of journalistic storytelling. Mudliar et al. (2013) studied how the use of mobile technologies enabled rural communities in India to become active participants in issues that they were facing. Previously excluded, with the discourse largely taking place on television and in newspaper editorials, an interactive voice forum called CGNet Swara allowed communities to record messages of local interest, as well as to listen to messages that others had recorded. Although seen as a tool for citizen journalism and public engagement, the research found that communities felt that it was a "tool that carries complaints forward and helps in their resolution" (ibid., 72).

The impact of equipping people with skills to report on what is going in their location is nowhere more prominent than in Egypt, where there has been a long history of bloggers and activists chronicling events and demonstrations against the then President Hosni Mubarak, which were not covered on mainstream media. The impact was clear with blogs becoming powerful sources of information and also lobbying with the ability to reach international audiences (Levinson 2005). However, concerns around government intimidation and fragmentation with competition is often addressed (Hamdy 2009; Isherwood 2008; Radsch 2008).

Hashtag Our Stories was formed in September 2017, with the company mission set out as follows: "A global network of mobile storytellers creating videos about people changing their worlds". With the same ethos as ContrastVR, Hashtag Our Stories has been working to equip people with the skills necessary to broadcast their stories on platforms that have a global audience. The company, led by Yusuf Omar, has trained more than 2,000 mobile journalists in 140 countries to tell mobile stories which are then curated on the company's social platforms. The plan for the organization is to cover stories and voices that are "specifically looked at, often been talked about, but seldom been talked to" (2019).

In a similar vein to the work at ContrastVR and Electric South, on-the-ground training in communities has meant that there are more journalists to do "good factual reliable and authentic journalism" (2019), reaching 6 million people across their social platforms. They believe this is a more authentic way than through the lens of foreign journalists, as replicated in the mission behind ContrastVR. As with Contrast VR and the research that emerged from citizen journalism in the Arab Spring, it is built on the idea that diversity in voices enables a more authentic journalistic voice. Despite operating with the digital divide, Omar believes projects like this are breaking the barriers of entry into the ecosystem.

\section{Concluding thoughts}

The genre of immersive journalism is very much still emerging. Studios and news organizations have been identifying ways of working and discussing how stories are 
best told and the editorial guidelines that should be followed (all discussed throughout this book). It is clear that there are no set rules yet and so immersive journalism is very much in a period of experimentation. The New York Times supported Daily 360 stories for a one-year period (2017-2018), and The Guardian developed a VR lab, before resting it whilst the industry finds its place. The implication of this is that journalists from all over the world can be experimenting to find the voice of immersive journalism, without being dominated by the narrative of Silicon Valley (Kopp 2019).

As has been evidenced through movements in video and mobile journalism, opening access to technology is diversifying narratives and including more perspectives into the journalistic voice. Through specific organizations operating in the Global South, training is being offered to diverse communities to enable an authenticity to storytelling that is not being delivered through a foreign lens. This is allowing journalism to expand on the mixed narratives that have emerged from digital journalism practices. Immersive journalism now sits alongside these with calls for access to technology to enable a narrative and experimentation with story forms that breaks the digital divide. It is clear in the case studies presented that this work is being done by ContrastVR and Electric South offering examples of where there is talent emerging within this technology. It is important for this work to be continued as digital technology breaks down barriers in making and consuming news, as indicated in Elite Truong's Nieman Lab Report (2016): "to ensure that news reports have impact, we'll need to connect with readers because we reflect the readers".

Immersive journalism is not just about taking audiences to places that they haven't been or to afford them the opportunity to "walk in someone else's shoes". It is about opening up technological barriers so there is diversity and inclusivity in the voices telling sto for a true immersive experience.

\section{References}

Afande 2018, in Electric South, www.electricsouth.com [Accessed 15 January 2020].

Berry, R. 2016. "Podcasting: Considering the evolution of the medium and its association with the word 'radio'." Radio Journal: International Studies in Broadcast \& Audio Media, 14(1): 7-22.

Biocca, Frank \& Mark R. Levy. 1995. "Communication applications of virtual reality." In: F. Biocca \& M.R. Levy (eds.), LEA's Communication Series: Communication in the Age of Virtual Reality. Hillsdale, NJ: Lawrence Erlbaum, pp. 127-157.

Bivens, R.K. 2008. "The Internet, mobile phones and blogging: How new media are transforming traditional journalism.” Journalism Practice, 2(1): 113-129.

Blankenship,J.C. 2016. "Losing their 'mojo'? Mobile journalism and the deprofessionalization of television news work." Journalism Practice 10(8): 1055-1071.

ContrastVR, in https://ajcontrast.com [Accessed 15 January 2020].

Cwynar, C. 2015. "More than a 'VCR for radio': The CBC, the Radio 3 podcast, and the uses of an emerging medium." Journal of Radio \& Audio Media 22(2): 190-199.

de la Peña, N., P. Weil, J. Llobera, E. Giannopoulos, A. Pomés, B. Spanlang, D. Friedman, M.V. Sanchez-Vives \& M. Slater. 2010. "Immersive journalism: Immersive virtual reality for the first-person experience of news." Presence: Teleoperators and Virtual Environments 19(4): 291-301. 
Guillen, M.F. \& S.L. Suárez. 2005. "Explaining the global digital divide: Economic, political and sociological drivers of cross-national internet use." Social Forces 84(2): 681-708. CiteSeerX 10.1.1.649.2813. doi:10.1353/sof.2006.0015

Hamdy, N. 2009. “Arab citizen journalism in action: Challenging mainstream media, authorities and media laws." Westminster Papers in Communication \& Culture 6(1).

Hamit, F. 1994. Virtual reality and the exploration of cyberspace. Carmel, Ind. Sams Publishing.

Heinrich, A. 2012. "Foreign reporting in the sphere of network journalism." Journalism Practice 6(5-6): 766-775.

Hernandez, R. 2017. "Virtual reality - the shift from storytelling to storyliving is real." https:// medium.com/journalism360/virtual-reality-the-shift-from-storytelling-to-storyliving-isreal-ff465c220cc3 [Accessed 15 January 2020].

ICFJ. 2017.www.icfj.org/sites/default/files/2018-04/ICFJTechSurveyFINAL.pdf [Accessed 5 January 2019].

Isherwood, T. 2008. "A new direction or more of the same?" Arab Media \& Society. September. Available at www.arabmediasociety.com/topics/index.php?t_article= 230\&p=1 [Accessed 5 January 2020].

Jones, S. 2017. "Disrupting the narrative: Immersive journalism in virtual reality." Journal of Media Practice 18(2-3): 171-185. doi:10.1080/14682753.2017.1374677

Joye, S. 2009. "The hierarchy of global suffering: A critical discourse analysis of television news reporting on foreign natural disasters." Journal of International Communication 15(2): 45-61.

Karhunen, P. 2017. Closer to the Story? Accessibility and Mobile Journalism. Oxford, UK: Reuters Institute for the Study of Journalism, University of Oxford.

Kemp, S. 2018. "Digital Use Suite.” https://wearesocial.com/blog/2019/01/digital-2019global-internet-use-accelerates [Accessed 15 January 2020].

Koponen, T. \& H. Väätäjä. 2009. September. "Early adopters' experiences of using mobile multimedia phones in news journalism." In; European Conference on Cognitive Ergonomics: Designing beyond the Product---Understanding Activity and User Experience in Ubiquitous Environments .VTT Technical Research Centre of Finland, p. 2.

Kopp, Ingrid. 2017. "Who is VR for? ” https://immerse.news/who-is-vr-for-20b3f077a912

Kovach, B. and T. Rosenstiel. 2014. The Elements of Journalism: What Newspeople Should Know and the Public Should Expect. California, CA:Three Rivers Press.

Krimsky, G.A. 2002. "The view from abroad: The foreign media are covering the war on terror through lenses that differ dramatically from those used by their American counterparts." American Journalism Review 24(1): 54-58.

Levinson, C. 2005. "Egypt's online voices of dissent.” Christian Science Monitor 13 (10 Oct.). www.alternet.org/story/24525 [Accessed 8 March 2019].

Mudliar, P., J. Donner, \& W. Thies. 2013. "Emergent practices around CGNet Swara: A voice forum for citizen journalism in rural India." Information Technologies \& International Development 9(2): 65.

Politico. 2018. "Digital Divide in America." Politico.com. www.politico.com/agenda/story/ 2018/02/07/digital-divide-in-america-graphic-000639 [Accessed 8 March 2019].

Quinn, S. 2013. Knowledge Management in the Digital Newsroom. Oxford, UK: Focal Press.

Radsch, C. 2008. "Core to commonplace: The evolution of Egypt's blogosphere." Arab Media E Society 6:1-14.

Rasoul, Z. 2018. "Contrast VR." https://medium.com/ajcontrast/welcome-to-contrastvrs-weekly-blog-52842a10d8a2

Rheingold, H. 1991. "Virtual reality: exploring the brave new technologies." Simon \& Schuster Adult Publishing Group. 


\section{Sarah Jones}

Sinclair, K. 2017. Weforum.org. www.weforum.org/agenda/2017/06/artificial-intelligencecode-better-world/ [Accessed 8 March 2019].

Steensen, S. 2010. "Online journalism and the promises of new technology: A critical review and look ahead." Journalism Studies 12(3): 311-327.

Tuchman, G. 1978. "Television news and the metaphor of myth." Studies in Visual Communication 5(1): 56-62.

Vázquez-Herrero J. \& X. López-García. 2017. "Immersive journalism through mobile devices: How virtual reality apps are changing news consumption.” In: Á. Rocha, A. Correia, H. Adeli, L. Reis, \& S. Costanzo (eds), Recent Advances in Information Systems and Technologies. WorldCIST 2017. Advances in Intelligent Systems and Computing 571. Cham, Switzerland: Springer.

Watson, Z. 2017. VR for News: The New Reality? Digital News Project. Oxford, UK: Reuters Institute for the Study of Journalism, University of Oxford.

Wenger, D., L. Owens, \& P. Thompson. 2014. "Help wanted: Mobile journalism skills required by top US news companies." Electronic News 8(2): 138-149.

Wood, W. 1986. "Consumer spending on the mass media: The Principle of Relative Constancy reconsidered.” Journal of Communication 36(2): 39-51. 